\title{
Os muitos olhares sobre o conceito de Hotel Boutique
}

\author{
The many perspectives on the concept of Boutique Hotels
}

\section{Los muchos puntos de vista sobre el concepto de Hotel Boutique}

\author{
Ana Carolina Barbosa Angeli ${ }^{1}$ \\ Ricardo de Gil Torres ${ }^{2}$ \\ Ricardo Frota de Albuquerque Maranhão ${ }^{3}$
}

\begin{abstract}
Resumo: O mercado hoteleiro investe com regularidade na renovação de seus empreendimentos. Neste momento de melhoria de suas instalações se apresenta uma oportunidade de reposicionamento mercadológico. O presente artigo apresenta uma pesquisa de caráter exploratório, que teve como objetivo geral verificar como o conceito de hotel boutique é entendido por pesquisadores de diferentes países. Em função da maior agilidade para a implantação de inovações, considerou-se a possibilidade do modelo de hotel boutique ser adotado por hotéis independentes como forma de melhorar sua competitividade em relação às grandes redes hoteleiras. Verificou-se que não existe um modelo único de hotel boutique, embora instalações de pequeno porte com design diferenciado e atendimento personalizado sejam uma constante nas descrições em que também é enfatizado o valor da experiência única.
\end{abstract}

Palavras-chave: Hospitalidade; Hotel Boutique; Renovação; Economia da experiência.

Abstract: The hospitality industry needs from time to time to renovate its installations. There is no better moment for a marketing repositioning. This paper presents an exploratory study on how the boutique hotel concept is understood by researchers from different countries. Due to independent hotels agility in implementing innovations, it was considered the possibility of part of this segment adopting the boutique model to improve competitiveness against hotel chains. It was found that there is no single understanding of boutique hotel meaning. Nevertheless, small and fancy hotels with unique design and customer service are usually considered boutique hotels. Unique experience is also mentioned as an ingredient to a boutique hotel.

Keywords: Hospitality; Boutique hotel; Renovation; Experience economy.

\footnotetext{
${ }^{1}$ Mestre em Hospitalidade pela Universidade Anhembi Morumbi (UAM). Professora do curso de Tecnologia em Hotelaria e Turismo da Universidade Nove de Julho (UNINOVE).E-mail: carolinaangeli@hotmail.com

${ }^{2}$ Doutor em Administração pela Escola de Administração de Empresas de São Paulo (EAESP) da Fundação Getulio Vargas (FGV). Professor do Mestrado em Hospitalidade pela UAM. E-mail: rgtorres@gvmail.br

3 Doutor em História e Mestre em Ciências Sociais pela Universidade de São Paulo (USP). Professor doutor da UAM na Graduação em Gastronomia, na Pós-graduação em Padrões Gastronômicos e no Mestrado em Hospitalidade. Coordenador do Centro de Pesquisas em Gastronomia Brasileira, atuando principalmente nos seguintes temas: Alimentação, Gastronomia, História da Alimentação e da Gastronomia, Cultura Brasileira e História do Brasil. E-mail: almalmaranhaz@terra.com.br
} 
Resumen: El mercado hotelero invierte regularmente en la renovación de sus empresas. En ese momento de mejora de sus instalaciones es cuando se ofrece la oportunidad de reposicionarse en el mercado. Este artículo presenta un estudio de investigación que tuvo como objetivo determinar cómo definen el concepto de hotel boutique especialistas de diferentes países. Debido a la mayor agilidad en la implementación de innovaciones, hemos considerado la posibilidad de que el modelo sea adoptado por los hoteles independientes de manera a mejorar su competitividad frente a las grandes cadenas. Se verificó que no existe un modelo único de hotel boutique, aunque construcciones pequeñas con design diferente y servicio personalizado sean una constante en las descripciones, las cuales también destacan el valor de la experiencia única.

Palabras clave: Hospitalidad; Hotel Boutique; Renovación; Economía de la experiencia.

\section{INTRODUÇÃO}

Um hotel pode se diferenciar, entre outras maneiras, por seu design, pela linha arquitetônica das construções e pela forma com que o empreendimento, seus equipamentos e ambientes se distribuem no espaço. Tamanho, localização, perfil do consumidor, tipo de gestão, se são nacionais ou internacionais, independentes ou operados por uma rede, são outras formas de diferenciação.

O desenvolvimento da hotelaria está fortemente ligado a hotéis independentes e de administração familiar para os quais existe um nicho de mercado tipicamente fidelizado com uma identidade própria (Dias, 1990; Chon \& Sparrowe, 2003). O mercado hoteleiro investe com regularidade na renovação de seus empreendimentos. A utilização do reposicionamento na época da renovação é um dos recursos para que os hotéis independentes possam competir com as grandes redes (Hassanien \& Baum, 2002).

Uma opção de renovação pode se direcionar aos hotéis boutique, que surgem como um dos desenvolvimentos mais interessantes no setor de hospitalidade, sendo atribuído ao processo de segmentação e diferenciação da hotelaria para os "[...] consumidores à procura de um número crescente de produtos e serviços para satisfazer suas necessidades de hospedagem" (Horner \& Swarbrooke, 2005, p.369).

A popularidade dos hotéis boutique é uma reação ao turismo de massa predominante dos anos 1970, "[...] caracterizado por um design internacional idêntico presente nas grandes redes de hotéis, atrações mercantilizadas e práticas rígidas de viagens" (Teo \& Chang, 2009, p.83). A busca por viagens de luxo tem causado um crescimento significativo no mercado de hospedagem de alto nível. Porém, a esse desenvolvimento do mercado de luxo se contrapõe uma nova tendência que é a ascensão da hospedagem barata no mercado da hotelaria (Christersdotter, 2005). A melhoria das condições econômicas e o aumento do tempo destinado ao lazer geram um infinito leque de possibilidades para o mercado hoteleiro (Minguet, 2005).

O hotel boutique surgiu nos Estados Unidos na década de 1980 e tem apresentado uma crescente popularidade (Wheeler, 2006). Segundo Christersdotter (2005), esses hotéis estão presentes em todos os segmentos de preço e são notadamente diferentes em aparência e 
concepção dos meios de hospedagem tradicionais. O termo hotel boutique foi sugerido por Steven Rubell, em 1984, ao ser perguntado sobre seu novo hotel, o Morgans de Nova York. Rubell disse que os outros hotéis eram grandes lojas de departamentos, ao passo que este era uma pequena boutique (Anhar, 2001; Asensio, 2004; Christersdotter, 2005; Wheeler, 2006).

Diante do exposto, este artigo busca verificar o conceito de hotel boutique como uma eventual estratégia de renovação para a hotelaria independente, considerando que os empreendimentos desse segmento têm mais flexibilidade para personalizar seus serviços, dedicando-se a mercados específicos. Trata-se de uma pesquisa bibliográfica, de caráter exploratório, levada a efeito a partir de levantamento de livros, dissertações e artigos de periódicos sobre o tema, em bases de dados nacionais e internacionais. O termo inicial de busca foi "hotel(eis) boutique(s)", em português, e "boutique hotel(s)" e "boutique accommodation(s)", em inglês. De um total de mais de cinquenta documentos iniciais, foram selecionados quinze que faziam referência direta a hotéis boutique em vários países, os quais se constituíram no objeto desta pesquisa. Após a leitura detalhada do conteúdo de cada documento, elaborou-se uma síntese e selecionaram-se trechos referenciais sobre a evolução, as características e os aspectos conceituais desses empreendimentos hoteleiros nos Estados Unidos, Inglaterra, Nova Zelândia, Romênia, África do Sul e Brasil.

Este artigo apresenta os resultados dessa investigação realizada de abril a setembro de 2011, iniciando-se pela exposição desse movimento em cada um dos países citados. Em seguida analisa as suas diferentes concepções, sintetizando-as em um quadro síntese representativo das visões dos autores referenciados, e discutindo-as como uma opção de renovação no âmbito da economia da experiência. Espera-se, com isso, contribuir para a melhor compreensão desse segmento hoteleiro em contraponto às categorias tradicionais de hotéis, e estimular outros estudos sobre a sua viabilidade na renovação da hotelaria independente no Brasil.

\section{RENOVAÇÃO E ECONOMIA DA EXPERIÊNCIA NA HOTELARIA}

A alta competitividade e a necessidade de diferenciação tornaram o cliente o foco e o centro da geração de valor para as empresas. De acordo com Powers e Barrows (2004, p.119), "[...] uma forma útil de examinar o produto da hospitalidade é entender que ele é a experiência do cliente".

Um meio de hospedagem será mais ou menos valorizado, e consequentemente obterá maior valor econômico, se os clientes o considerarem como tal. Não é a empresa quem estabelece valor. O valor decorre da percepção dos clientes (Prahalad \& Ramaswamy, 2004). Gilmore e Pine (2002, p.88) afirmam que:

Conforme os hotéis se tornaram mais parecidos do que diferentes, desde os conceitos básicos que dominam a sua concepção física, até os procedimentos operacionais, rapidamente viram seus negócios comprados principalmente com base no preço. Ao longo dos anos, muitos hotéis foram atingidos pela 
padronização e eles cresceram cada vez mais semelhantes nas convenções que praticam. A gestão de hotéis como locais de experiência (ao invés de simplesmente propriedades) ajuda a vencer a armadilha da mercantilização.

Qualquer estágio do produto ou do serviço hoteleiro pode ser aproveitado para causar uma nova experiência:

A essência da experiência é que ela requer envolvimento ou participação da pessoa que está envolvida [...] experiências são internas por natureza e, portanto, de natureza individual. Isso faz com que o marketing, medição e gerenciamento da experiência em um hotel sejam tão difíceis (Knutson et al., 2009, p.44).

A renovação de propriedade é um dos instrumentos mais importantes para a inovação de produtos no ramo da hotelaria. A renovação, se bem planejada e bem implementada, poderá alcançar o aumento do lucro, a satisfação do cliente e, provavelmente, a liderança de mercado (Hassanien \& Baum, 2002). Segundo Luz (1999, p.137), “[...] os hotéis precisam investir com regularidade em modernização de suas instalações e na manutenção de sua infraestrutura como forma de manter ou expandir a participação de mercado".

Chon e Sparrowe (2003) afirmam que alguns proprietários de cadeias hoteleiras perceberam que poderiam investir o dinheiro da receita na renovação do empreendimento e consequentemente valorizá-lo para reconquistar fatias do mercado ou para reposicionar o empreendimento a fim de conquistar novos clientes. Os autores sinalizam que algumas reformas nos empreendimentos hoteleiros são inevitáveis para se adequar as novas exigências legais e outras reformas são necessárias para manutenção.

A renovação envolve as atividades associadas com o desenvolvimento e/ou modificação física do hotel, a fim de prolongar a vida útil do imóvel para mantê-lo competitivo, para melhorar a eficiência operacional da propriedade e para construir uma melhor imagem do empreendimento no mercado. A renovação é uma necessidade dispendiosa, contínua e essencial para os hotéis. 0 mercado hoteleiro investe com regularidade na renovação de seus empreendimentos, seja através da melhoria de suas instalações, seja no seu reposicionamento mercadológico. Todos os hotéis já foram renovados, estão em processo de renovação, ou estão à espera desse processo (Hassanien \& Baum, 2002).

Verifica-se que a principal característica do turismo no mundo atual é o desenvolvimento de experiências de viagem para uma série de indivíduos que desejam ver, entender e experimentar a natureza de destinos diferentes e a forma como as pessoas vivem e trabalham nestes destinos (Ritchie et al., 2010).

A experiência hoteleira pode ser entendida na pessoa do turista que, ao mesmo tempo em que espera encontrar um produto ou um serviço conhecido, também sente vontade de fugir da rotina e de buscar o inusitado. As empresas que forem além da excelência nos serviços e compreenderem essa nova fase da experiência no turismo, assumirão a liderança na criação de um novo valor para o setor da hospitalidade (Gilmore \& Pine, 2002). 
Atualmente, o mercado hoteleiro brasileiro é dividido em redes hoteleiras e hotéis independentes que se subdividem em empresas nacionais e internacionais e que possuem administração familiar ou são operados por uma rede. O hotel independente pode ser conceituado como uma empresa individual com administração familiar e em envolvimento direto com os setores operacionais, comercial e administrativo, onde predominam baixos níveis de controles operacionais e nenhuma padronização de serviços (Duarte, 1996). São hotéis compostos de uma unidade hoteleira, geralmente pertencente a um único dono ou família e sem filiais (Cândido \& Vieira, 2003).

As eventuais vantagens da hotelaria independente, em comparação com as redes hoteleiras, residem na liberdade de administração, nas tomadas de decisões que são realizadas com maior rapidez e na liberdade para criar e implementar novas ideias que levam o hotel independente a saídas inovadoras e atraentes para os hóspedes. Para um hotel independente, trabalhar um nicho de mercado se torna atraente, pois ao operar em mercados específicos, satisfazendo um grupo seleto de clientes e buscando desenvolver produtos para esse mercado, pode aproveitar melhor suas vantagens competitivas.

As desvantagens dos hotéis independentes são possíveis deficiências de administração como, por exemplo, resistência à modernização de equipamentos, infraestrutura e sistemas, e falta de experiência em processos operacionais e de investimento na capacitação profissional e tecnológica (Chon \& Sparrowe, 2003; Castelli, 2001; Oliveira, 1999).

\section{HOTÉIS BOUTIQUE EM VARIOS PAÍSES: CONCEPÇÃO E CARACTERIZAÇÃO}

\section{Estados Unidos}

O conceito de hotel boutique surgiu na década de 1980 nos Estados Unidos, com a remodelação do Clift Hotel em São Francisco por lan Schrager, mantendo as características principais do hotel e introduzindo o design especial que caracteriza seu estilo e decoração, tornando o ambiente aconchegante e quase informal (Campos, 2005). Esta ênfase no design intimista caracteriza os hotéis boutique desde seu início, pois de acordo com Schrager (como citado em Campos, 2005) era impossível trabalhar o hotel boutique em uma escala maior, atendendo a um público heterogêneo e oferecendo espaços para convenções.

Anhar (2001), Vallen e Vallen (2003), Asensio (2004), Wheeler (2006) e Russell (2008) analisam em especial as características dos hotéis boutique nos Estados Unidos. Embora não exista consenso entre os autores, e o tamanho deste tipo de hotel nos Estados Unidos varie consideravelmente, a maioria dos hotéis boutique compartilha algumas características comuns, como a busca pela experiência da hospedagem e a personalização dos serviços. Verifica-se que, assim como ocorre com qualquer produto de hospitalidade, o sucesso dos hotéis boutique começa com os passos fundamentais da hotelaria, tais como: localização do empreendimento, qualidade do produto, identificação da demanda de mercado, abordagem de marketing bem definida e ações eficazes de distribuição e cobertura de reservas (Anhar, 2001). 
Conforme Anhar (2001), o conceito de hotel boutique varia no mercado hoteleiro norte americano, porém algumas características como estilo, distinção, receptividade e intimidade são consideradas palavras-chave na arquitetura e design desses hotéis, que buscam atrair um segmento de clientes que procura um local diferenciado e especial para se hospedar. Essa visão é compartilhada por Asensio, (2004, p.6) para quem o hotel boutique é "[...] uma nova tendência em gestão e design. Alguns preferem chamar de "pequeno [hotel de] luxo", outros de design e alguns preferem chamar de cool".

Para Vallen e Vallen (2003, p.45) os hotéis boutique são uma espécie única de hotel. São empreendimentos pequenos, com 10 a 30 apartamentos, e todas as vantagens de um bom hotel sem, contudo, o porte avantajado e a agitação. Para os autores, esse tipo de hotel é elegante, sendo encontrado em excelentes localizações urbanas. Wheeler (2006) o identifica como uma tendência para o setor hoteleiro em geral e afirma que:

- Hotel boutique é um termo originário da América do Norte para descrever intimidade, geralmente em ambientes luxuosos ou peculiares.

- Os primeiros hotéis boutique começaram a surgir em meados da década de 1980, por meio de empreendedores que não se consideravam apenas hoteleiros, mas, também, formadores de opinião.

- O modelo hotel boutique, que transformou a indústria de viagens por meio da introdução de design sofisticado, preços elevados e hospedagem de celebridades, atualmente mostra sinais de crescimento contínuo no mercado hoteleiro.

- Hotéis boutique diferenciam-se de hotéis de rede, pois fornecem acomodações e serviços personalizados.

Segundo Russell (2008), esses hotéis utilizam as características e o charme do velho mundo em um edifício histórico renovado, criando uma elegante e moderna propriedade. Eles são populares entre os hóspedes, pois cada um oferece uma experiência de hospedagem única e personalizada. Para Wheeler (2006), o aumento do número de hotéis boutique pode se dever à oferta restrita de novos hotéis. A renovação de edifícios antigos tem o potencial de oferecer uma sensação única de hospedagem, misturando um design de interior contemporâneo em um cenário, algumas vezes, histórico. Isso produz uma experiência única pela qual os consumidores estão cada vez mais atraídos.

O crescimento dos hotéis boutique nos Estados Unidos tende a continuar e a concentrar-se em localidades urbanas, com a preservação ou recuperação de edifícios antigos ou históricos, onde as características do local não permitem a implantação de um hotel de rede. Essa situação possibilita alavancar a capacidade de comercialização dos hotéis boutique no que diz respeito à sua relevância cultural (Wheeler, 2006).

O hotel boutique parece existir em ambientes que permitam a "reutilização adaptativa" de pequenos prédios e edifícios antigos e naqueles em que há uma massa crítica de hóspedes em potencial sensíveis à imagem agregada, permitindo auferir vantagem desta característica. Uma explicação para este movimento, segundo Wheeler (2006), pode estar no fato de que o interesse 
pelo estilo e design evoluiu, influenciando a escolha das pessoas na hora de optar por um produto hoteleiro. O consumidor parece disposto a pagar um valor adicional para ficar em um hotel que ofereça uma sensação exclusiva de hospedagem. Para o autor, um hotel boutique deve ter menos de 200 quartos e menos de 650 metros quadrados de área comum, e ser focado nas amenidades e níveis extremamente elevados de oferta de serviço.

Anhar (2001) sugere que um grande número de clientes fica hospedado em hotéis boutique porque estes estão na moda, e não devido aos outros atrativos que oferecem. Por este ponto de vista, os hotéis boutique são comercializados de forma semelhante a muitos outros produtos, nos quais a experiência e a imagem são vendidas com mais ênfase, até, que o próprio produto.

Wheeler (2006) verificou que há um aumento da procura por pequenos hotéis e acredita que essa tendência continuará, uma vez que viajantes de luxo rejeitam a homogeneidade de estabelecimentos padronizados, em favor daqueles que Ihes proporcionam uma experiência única e individualizada. O autor constatou ainda que, nos Estados Unidos, as empresas atuantes no mercado de hotéis boutique têm procurado caracterizar suas propriedades como hospedagens da moda, não só no que tange aos seus serviços, mas também no que se refere à percepção de imagem junto ao público. Normalmente, estas empresas direcionam os esforços para o consumidor que valoriza o estilo e a imagem, e está disposto a pagar por estes atributos.

Possíveis mudanças no interesse dos consumidores americanos são discutidas pelos autores, bem como o significado mais amplo do "movimento hotel boutique". Uma explicação possível, verificada por meio da pesquisa de Wheeler (2006), pode ser a influência de outras culturas sobre a cultura americana, aumentada pela globalização. Além da questão física e estética, nos hotéis boutique percebe-se a preocupação com serviços diferenciados, atendimento personalizado e produtos exclusivos, o que resulta em uma experiência importante que pode gerar a fidelidade do cliente. Anhar (2001) afirma que o que os distingue dos meios de hospedagem tradicionais é a conexão que os hóspedes passam a ter com os membros da equipe do hotel. Russell (2008) relata que o hotel boutique é tipicamente pequeno, proporcionando um ambiente moderno e uma ligação pessoal entre hóspedes e equipe de trabalho.

Os pequenos espaços do hotel boutique são uma reminiscência dos hotéis menores encontrados em toda a Europa. Como o típico americano se sente mais ligado ao resto do mundo em função dos recentes avanços tecnológicos, pode haver uma tendência natural de aproximação sob esta influência, gerando uma busca por itens de maior valor cultural e interesse pessoal. Os hotéis boutique podem se beneficiar desta mudança na preferência dos consumidores norteamericanos (Wheeler, 2006).

Vallen e Vallen (2003) verificaram que os hotéis boutique nos Estados Unidos, assim como em outros países, são empresas que funcionam em tempo integral e requerem grandes investimentos de capital. Ademais, para que o hotel boutique possa obter um retorno razoável, considerando ser um investimento não convencional no mercado hoteleiro, é preciso que os preços das diárias sejam próximos aos de alguns estabelecimentos quatro ou cinco estrelas. 


\section{Inglaterra}

Os hotéis boutique britânicos parecem estar em melhor forma comercial do que cadeias de hotéis tradicionais. Entretanto, o segmento boutique do mercado avalia que as características que Ihe são atribuídas estão abaixo do ideal, embora continuem a adotá-las como referência por três razões: a) fornecem uma tendência em comum e, portanto, permitem o debate; b) são amplamente utilizadas nos Estados Unidos, o maior mercado hoteleiro mundial; e c) os dados do mercado hoteleiro internacional são recolhidos e analisados com base no sólido setor hoteleiro norte-americano (Lea, 2002).

No entender de Christersdotter (2005), o hotel boutique é um produto com foco no estilo de vida de seu consumidor, com design e características arquitetônicas muito peculiares:

Hotel boutique é uma nova categoria de estabelecimento no setor hoteleiro que tem sido descrito como casas urbanas ou pequenas propriedades cheias de estilo e ligadas à moda, desenvolvidas sob o conceito de boutique de roupas dos anos 1960, com base na comercialização de produtos e mercadorias exclusivas. A este respeito, o hotel boutique é um produto com foco no estilo de vida de seu consumidor, com design e características arquitetônicas únicas (Christersdotter, 2005, p.75).

A entrada das redes para o mercado de hotel boutique na Inglaterra pode ser uma contradição, comprometendo-se a característica essencial de individualidade de cada hotel pela homogeneidade dos princípios da rede que faz com que a experiência seja uniforme em cada estabelecimento, independente da sua localização (Christersdotter, 2005).

No que se refere à estrutura física, no entanto, Lea (2002) nota que o maior risco que as cadeias hoteleiras enfrentam reside justamente em tentar equalizar os conceitos de boutique em um estabelecimento operacionalmente padronizado. "O design moderno é, frequentemente, uma característica desse novo modelo de hospedagem, embora não seja a única” (Lea, 2002, p.36). Há também as individualidades - de hóspede, de proprietário, de localização, de funcionários, de atmosfera do hotel - que se refletem no design, mas não necessariamente são fruto do design. Os hotéis boutique não têm manutenção e custos de reparos padronizados, mas as características positivas normalmente superam os custos operacionais, devido ao processo de melhoria contínua, que é visivelmente mais flexível que nos hotéis de rede. Alguns proprietários ainda reduzem os custos de adaptação dos hotéis boutique por meio da adoção de uma estratégia de quanto menos, melhor (Christersdotter, 2005).

Em alguns casos, esses custos são reduzidos diminuindo os níveis de serviços, compensando-os com suas características de estilo e apresentando os serviços limitados como elemento positivo. A tendência de hotel boutique, entretanto, já se espalhou para resorts e também já existe no modelo de baixo orçamento - barato e chique. Em determinados hotéis boutique, não há serviço de quarto e existem poucos atrativos na parte de alimentos e bebidas (Christersdotter, 2005). 
Segundo Aggett (2007), os consumidores entendem o hotel boutique como algo além da simples acomodação, identificando-o como local que pode proporcionar uma experiência única em termos de hospedagem. Assim como afirma Christersdotter (2005), os hotéis boutique desafiam as tradicionais classificações de estrelas na hotelaria e buscam atrair o consumidor que procura uma experiência única, diferente daquela oferecida pelas cadeias convencionais. $O$ crescimento do segmento de hotel boutique também pode ser atribuído aos consumidores que buscam uma alternativa à oferta padronizada da hospedagem e que procuram por uma opção especial ou com exclusividade. Para Aggett (2007), são cinco os principais atributos de atração dos clientes para a hospedagem em hotel boutique: a) localização; b) qualidade; c) exclusividade; d) serviços prestados; e) níveis personalizados na oferta de serviços.

Hotel boutique é um novo segmento que não segue, necessariamente, as regras antigas da hotelaria tradicional e busca se estabilizar no mercado, mais do que simplesmente utilizar o termo boutique, o qual "[...] sugere pequenez e moda de uma forma bastante ampla e talvez contenha feminilidade demais para se manter" (Lea, 2002, p.39). Esse segmento representa uma mudança nítida de normas, atropelando a mesmice e a uniformidade num setor em que a classificação era feita com base no tamanho, tabela de preços, localização, rede hoteleira ou propriedade independente. Uma melhor identificação dos hotéis boutique pode se basear em outras características como, por exemplo, atmosfera familiar, serviço altamente personalizado e estilo distinto com muitas comodidades.

Segundo Aggett (2007, p.169), “[...] parece haver uma margem de desenvolvimento do segmento de hotel boutique, resultando em um crescimento alternativo e até mesmo superando o negócio de hospedagem convencional no Reino Unido". Horner e Swarbrooke (2005, p.369) destacam algumas características diferenciadoras dos hotéis boutique em relação à hotelaria tradicional: a) são menores e mais intimistas; b) dão ênfase ao design de móveis e acessórios como parte de uma identidade própria; c) utilizam estilos modernos contratando designers específicos para desenvolver os conceitos de serviço personalizado, mesmo nem sempre dispondo de instalações e serviços completos como bares e restaurantes.

Lim e Endean (2009, p.39) acreditam que delimitar uma definição precisa para hotel boutique resultaria em "[...] beneficiar organismos de comércio e associações ao rever seus sistemas de classificação e também proporcionar maior clareza para os setores que compõem a indústria hoteleira".

\section{Nova Zelândia}

Mcintosh e Siggs (2005) pesquisaram os hotéis boutique na Nova Zelândia e identificaram cinco dimensões que diferenciam o setor das ofertas tradicionais no país: a) o caráter único da propriedade; b) o toque pessoal; c) o ambiente acolhedor do alojamento; d) a alta qualidade dos padrões oferecidos; e) a natureza de valor agregado da localização e do conhecimento e cultura dos anfitriões. 
Referindo-se à estrutura física dos empreendimentos, as pesquisadoras fazem alusão ao fato de que alguns hotéis boutique usam prédios históricos ou com aspectos históricos como sendo a base da experiência que fornecem aos hóspedes. A qualidade da estrutura física e a atenção aos detalhes são características que, no país, os diferenciam dos estabelecimentos mais tradicionais.

Mcintosh e Siggs (2005) verificaram que o serviço personalizado não só é considerado fator de motivação nas decisões dos hóspedes para escolha de um hotel boutique, como leva alguns clientes a escolherem este tipo de hospedagem justamente por causa do atendimento. As autoras mencionam, também, a ênfase na privacidade como um elemento de sucesso do modelo que, em alguns casos, não é tão valorizado nos hotéis tradicionais.

Ainda para Mcintosh e Siggs (2005), os aspectos sobre a experiência de hospedagem permanecem relativamente inexplorados, especialmente quando relacionados às opções não convencionais de hotéis, e afirmam que a hospedagem é uma extensão da experiência no turismo, mesmo que ela não possa agir como fator determinante da motivação de viagem. Manter-se longe da oferta de produtos de hospedagem padronizados, como é política de muitos hotéis, é, sem dúvida, uma questão importante para o sucesso dos hotéis boutique, visto que, aparentemente os turistas procuram integrar e alinhar a escolha de acomodação com suas motivações gerais para a viagem. Para as pesquisadoras, no entanto, as características mais detectadas como decisivas para a opção são simplesmente que os hotéis boutique são individuais, centrados no design e baseados em operação de pequeno porte. Embora a definição do hotel boutique seja contestada, conforme verificado pelas autoras, ela envolve, geralmente, uma experiência de alojamento exclusiva, com ênfase na singularidade da estrutura física, nos elevados padrões de serviço e na atenção individual dada aos hóspedes.

\section{Romênia}

Uma pesquisa feita na Romênia por Rabontu e Niculescu (2009) revelou que os hotéis boutique do país são uma alternativa ao modelo das redes hoteleiras que oferecem centenas de quartos e atmosfera impessoal. Os hotéis boutique, naquele país, são de tamanho reduzido, localizados em uma área de prestígio, decorados com mobiliário diferenciado, em ambiente íntimo e familiar. São, ainda, diferenciados pelo design, pela atenção especial dada aos clientes e pelos serviços personalizados.

Em uma tentativa de definir o termo hotel boutique, Rabontu e Niculescu (2009, p.209210) afirmam que:

[...] é um hotel pequeno, com quartos luxuosos, mobiliados para receber, principalmente, turistas por curtos períodos. Hotel boutique é um termo que abrange um novo mundo de significados. Isso indica uma nova maneira de olhar a hospitalidade: uma recepção amigável e com serviços personalizados. 
Na Romênia, assim como na Inglaterra, a nomenclatura deste tipo de hotel também pode diferir dependendo do projeto, ou seja: a) hotéis com design contemporâneo são chamados hotéis design; b) hotéis com design clássico são denominados hotéis boutique.

No que se refere à estrutura física, estes hotéis são, geralmente, exclusivos em termos de design e são projetados com muito apreço a uma temática central. Esse cuidado é perceptível desde os ambientes internos até as áreas comuns, segundo os autores. Nota-se que os hotéis boutique têm um design exclusivo, contando com grande personalidade. Sendo menores em tamanho, podem oferecer privacidade e discrição aos clientes. "Os hotéis boutique buscam conhecer bem seus clientes e oferecer um serviço personalizado, algo que grandes hotéis não podem garantir aos seus hóspedes" (Rabontu \& Niculescu, 2009, p.210).

Segundo os pesquisadores, assim como na América do Norte, de onde vem o conceito hotel boutique, este tipo de hospedagem oferece mais que serviços de luxo, ganhando notoriedade por meio do design e da intimidade que proporciona; e justifica, novamente, o número reduzido de quartos e a capacidade de servir mais proximamente os seus clientes.

Os hotéis boutique, na Romênia, são frequentados, principalmente, por empresários, que representam aproximadamente $80 \%$ dos clientes. Nem todos os turistas têm acesso a esse tipo de hotel, que demanda investimento financeiro elevado. Rabontu e Niculescu (2009) apontam a necessidade de se promover este segmento para o mercado de massa, uma vez que a publicidade utilizada pelas grandes cadeias hoteleiras não tem este propósito e alguns hotéis boutique passam despercebidos aos olhos do público, tanto fisicamente como em termos de negócios. Eles podem ser encontrados apenas em guias especializados ou agências de turismo.

Rabontu e Niculescu (2009) verificam ainda, na Romênia, certa escassez de negócios de hospedagem em geral e sugerem que no futuro se tornará vantajosa a participação no mercado de hotéis com pequeno número de quartos, mas com personalidade. Para os autores, a tendência do mercado será de aumento no número de pequenos hotéis, não necessariamente de luxo ou boutique. Também, na opinião dos pesquisadores, prevalece a ideia de que o número de unidades três estrelas com serviços quatro estrelas irá avançar rapidamente, mesmo se ainda houver espaço no mercado para empreendimentos quatro e cinco estrelas.

\section{África do Sul}

Rogerson (2010) mostra os principais aspectos dos hotéis boutique na África do Sul. Segundo a autora, o surgimento e a expansão da hotelaria boutique devem ser atribuídos ao crescimento do setor hoteleiro sul africano como um todo. A evolução das diferentes formas de hospedagem é uma resposta direta aos mercados em mudança e a variação nos produtos hoteleiros é muito importante para novas tendências de consumo que rejeitam o caráter homogêneo e tradicional de parte do setor.

A autora verificou que a maioria dos hotéis boutique na África do Sul localiza-se em áreas urbanas das grandes cidades. Conforme sua pesquisa identificou, poucos são os estabelecimentos 
construídos originalmente como hotéis boutique. A maioria dos empreendimentos em operação neste segmento foi ampliada, modernizada ou renovada para se tornar boutique. Seguindo as tendências internacionais desse modelo de hospedagem, a estrutura física da maioria dos estabelecimentos na África do Sul é relativamente pequena. A ênfase no hotel boutique local está na excelência da prestação de serviços, a individualidade, a exclusividade e a privacidade que só são possíveis através do desenvolvimento de pequenos estabelecimentos.

Verificou-se que o consumidor de hotel boutique na África do Sul é, em sua maioria, o turista estrangeiro que viaja a lazer e busca uma nova experiência de hospedagem. Muitas vezes a equipe de trabalho dos hotéis desenvolve relações pessoais com os hóspedes, conhecendo seus nomes e preferências individuais. Segundo Rogerson (2010), as principais características do hotel boutique estão relacionadas com o tamanho, o padrão dos serviços prestados e a localização dos estabelecimentos.

O desenvolvimento dos hotéis boutique na África do Sul foi apoiado no início por investidores individuais e grupos de investidores. Só recentemente os hotéis de rede passaram a investir no segmento boutique. O sistema oficial de classificação do país não tem uma categoria específica para hotéis boutique, alimentando uma questão polêmica entre os estudiosos do setor. Como os seus pares internacionais, os investidores de hotéis boutique na África do Sul têm procurado distinguir este novo produto turístico com base em suas qualidades de experiência, com forte ênfase no design, ambiente diferenciado e oferta de serviços personalizados (Rogerson, 2010).

\section{Brasil}

A tendência, no Brasil, à concentração e centralização de negócios em torno de poucas redes hoteleiras, se dá em meio à contra tendências que abrem espaços para os hotéis independentes.

Estes hotéis utilizam-se de estratégias diferenciadoras oferecendo serviços exclusivos ou personalizados: são os hotéis design ou boutique, que enfatizam seu pequeno porte e as características locais como a arquitetura, o serviço, o atendimento e a decoração para enriquecer e diferenciar seu produto (Proserpio, 2007, p.225).

Por sua vez, Campos (2005, p.77) argumenta que:

A ideia inicial dos hotéis boutique era atrair o chamado segmento dos quatro $\mathrm{M}$ : movie, music, model e money. Para os criadores do estilo, o denominador comum é o estilo de vida das pessoas desses segmentos quatro $M$, que é contrário à rigidez dos hotéis convencionais. No conceito original, o design é avançado, os funcionários têm a aparência de manequins, falam diversos idiomas e conhecem antecipadamente os costumes e desejos dos hóspedes. 
Para Proserpio (2007), alguns hotéis boutique atuam no segmento de pequeno porte, pelo qual as redes hoteleiras não se interessam. Cada hotel desse tipo tem sua própria característica e estilo de decoração diferente para cada apartamento. "Podemos encontrar entre hotéis boutique, desde antigas moradias europeias inteligentemente adaptadas para hotelaria, até os mais modernos prédios com estilos de decoração completamente clean" (Campos, 2005 p.77).

Campos (2005) acrescenta que a oferta de serviços diferenciados é, em geral, levada a sério nos hotéis boutique. A equipe de trabalho busca saber de todos os gostos do hóspede para satisfazê-lo antes que ele possa perguntar ou pedir pelo produto ou serviço de sua preferência. Esses estabelecimentos fogem da padronização de serviços disponibilizados pelas grandes redes, oferecendo justamente o contrário: a personalização ou individualização dos serviços, visando atender a demandas específicas (Proserpio, 2007).

Todavia, Campos (2005) assinala que mesmo as grandes redes procuram uma forma de entrar no atendimento aos quatro M. A rede Sheraton criou o W Hotel e a rede Méridien tem o conceito de art and tech para algumas de suas unidades. No Brasil, pelo menos uma construtora, a Estanplaza, tomou para si a construção desse tipo de empreendimento que convencionou chamar de hotéis boutique. Ela criou essa linha e tem investido no segmento de hotéis executivos estrategicamente localizados na cidade de São Paulo.

\section{Síntese analítica das diferentes abordagens}

A busca pela padronização sistemática dos serviços hoteleiros iniciou um movimento contrário em direção ao estabelecimento e crescimento do formato que se denominou hotel boutique. Este movimento foi inspirado a partir da busca dos consumidores por hotéis com características únicas e inovadoras.

Verificou-se que alguns fatores promovem o crescimento contínuo de hotéis boutique, como por exemplo: a) a internet, tornando mais simples para os clientes o acesso à informação sobre este novo conceito em hospedagem; b) um número de grandes redes de hotéis entrando neste mercado; c) estilo e contemporaneidade, com uma concepção única de hospedagem repleta de amenidades; d) "reutilização adaptativa" de prédios urbanos antigos; e) espaços menores para quartos e área comum.

As características que identificariam os hotéis boutique, permitindo a criação de uma certificação padronizada para este modelo de hospedagem, ainda não são um consenso. A tendência para a hotelaria é a busca crescente por estabelecimentos com características próprias e identidade única, onde o hóspede possa sentir a personalização do serviço. É o diferencial intangível, quase impossível de ser copiado pela concorrência, que sustenta o empreendimento hoteleiro em longo prazo. A Figura 1 sintetiza as ideias dos autores referenciados neste artigo em uma tentativa de caracterização dos hotéis boutique. 


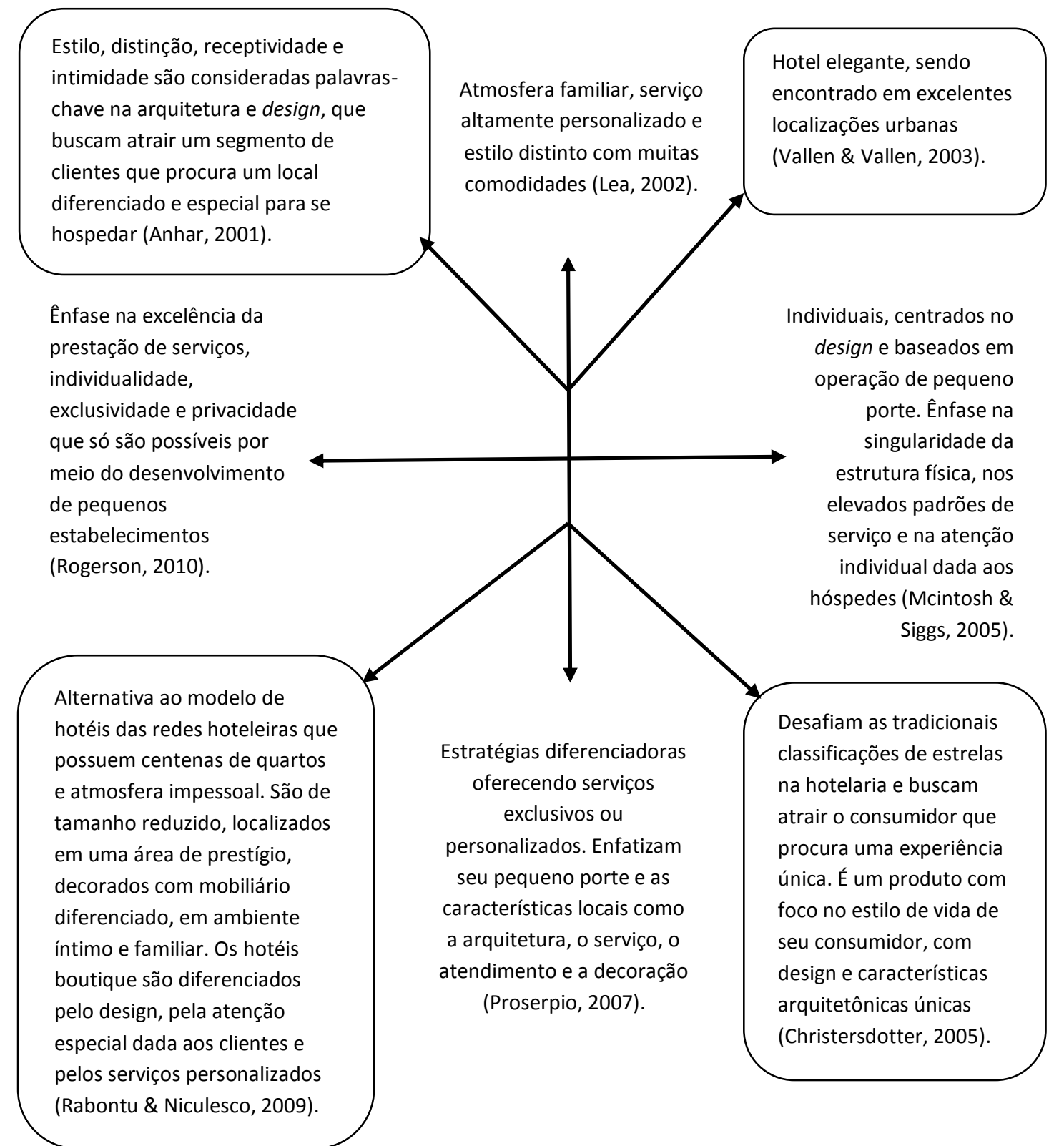

Figura 1. Caracterização dos hotéis boutiques na visão de diferentes autores Fonte: Elaboração própria.

Percebe-se por essa síntese que não há uma definição clara do que vem a ser um hotel boutique, cujo termo pode ser inclusive contestado. No entanto, analisando a visão dos autores referenciados na Figura 1, considera-se que esse tipo de empreendimento hoteleiro refere-se a uma "experiência de alojamento exclusiva", com ênfase na singularidade estilística, elevados padrões de serviço e atenção individual aos hóspedes. Compreende-se que um hotel boutique deve necessariamente ter instalações ditadas pelas características de design, com um projeto arquitetônico diferenciado ou instalado em um prédio histórico. Busca-se um elemento criativo e individual a respeito da propriedade e dos serviços oferecidos, ou seja, padrões pré-estabelecidos pela hotelaria não se encaixam neste tipo de propriedade. 


\section{CONSIDERAÇÕES FINAIS}

Deparou-se com um grande desafio, o de selecionar alguns estudos referenciados, de forma a orientar a análise e discussão da concepção dos hotéis boutique. O conceito de hotel boutique e a evolução desse segmento são pouco tratados na literatura especializada sobre hotelaria, e quando abordado apresenta insuficiência de fundamentação teórica.

As concepções analisadas indicam diferentes concepções, com superposições e contradições de um segmento hoteleiro promissor que se encontra em expansão em vários países em contraposição à atuação das grandes redes hoteleiras e sua respectiva padronização de serviços. Ficou claro que não existe uma definição geral de hotel boutique na qual se possa basear, mas existem características que o definem em diferentes mercados.

Para compreender o valor dos hotéis boutique uma análise deve ser considerada para cada mercado como sendo um mercado único, pois o desempenho de um hotel boutique em uma localidade não é indicativo de sucesso potencial do modelo em outro local.

Um hotel pode se diferenciar a partir de suas características do design, da linha arquitetônica das construções, e a forma pela qual o empreendimento e seus equipamentos e ambientes se distribuem no espaço. O mercado hoteleiro investe com regularidade na renovação de seus empreendimentos, seja através da melhoria de suas instalações, seja no seu reposicionamento mercadológico.

O hotel independente sobrevive da inovação dos produtos e serviços e de sua habilidade em saber se diferenciar no mercado enquanto as redes hoteleiras tendem à previsibilidade. $A$ transformação de um hotel independente em um hotel boutique segue esta oportunidade de inovação e reposicionamento, mas deve ser planejada e implantada antes do declínio do seu ciclo de vida, como uma estratégia de criação de um novo produto ou serviço.

Nesse sentido, há necessidade de novos estudos e pesquisas sobre esse movimento em outros países, notadamente na América Latina, ao lado da melhor compreensão da dinâmica e realidade dos hotéis independentes no Brasil.

\section{REFERÊNCIAS}

Aggett, M. (2007). What has influenced growth in the UK's boutique hotel sector? International Journal of Contemporary Hospitality Management, 19(2), 169-177.

Anhar, L. (2001, December 13). The definition of boutique hotels. Hospitality Net. Recuperado em 12 de outubro de 2012, de http://www.hospitalitynet.org/news/4010409.html.

Asensio, F. (2004). Cool hotels America. New York: Ed. TeNeues.

Campos, J. R. V. (2005). Introdução ao universo da hospitalidade. Campinas: Papirus.

Cândido, I., \& Vieira, E. V. (2003). Gestão de Hotéis: técnicas, operações e serviços. Caxias do Sul: EDUCS.

Castelli, G. (2001). Administração Hoteleira. Caxias do Sul: EDUCS. 
Chon, K. S., \& Sparrowe, R. T. (2003). Hospitalidade: conceitos e aplicações. São Paulo: Pioneira Thonson Learning.

Christersdotter, M. (2005). Transformers: Hip Hotels and the Cultural Economics of Aura-production. In O. Lofgren, \& R. Willim (Eds.). Magic, culture and the new economy (pp. 73-86). Oxford: Berg Publishers.

Dias, C. M. M. (1990). Home Away from Home. Evolução, caracterização e perspectiva da hotelaria: Um estudo compreensivo (Dissertação de Mestrado). Universidade de São Paulo - Escola de Comunicação e Artes, São Paulo.

Duarte, V. V. (1996). Administração de Sistemas Hoteleiros: conceitos básicos. São Paulo: Editora SENAC.

Gilmore, J. H., \& Pine II, B. J. (2002, June). Differentiating hospitality operation via experiences: why selling services is not enough. Cornell Hotel and Restaurant Administration Quarterly, 43(3), 87-96.

Hassanien, A., \& Baum, T. (2002). Hotel innovation through property renovation. International Journal of Hospitality \& Tourism Administration, 3(4), 5-24.

Horner, S., \& Swarbrooke, J. (2005). Leisure Marketing: a global perspective. Oxford: Elsevier.

Knutson, B. J., Beck, J. A., Kim, S., \& Cha, J. (2009, February). Identifying the dimensions of the guest's hotel experience. Cornell Hotel and Restaurant Administration Quarterly, 50(1), 44-50.

Lea, K. (2002). Boutique hotel: fad or phenomenon? Locum Destination Review. 7, 34-39.

Lim, W. M., \& Endean, M. (2009). Elucidating the aesthetic and operational characteristics of UK boutique hotels. International Journal of Contemporary Hospitality Management, 21(1), 38-51.

Luz, M. C. V. (1999). Panorama Setorial da Gazeta Mercantil. Análise Setorial: A Indústria Hoteleira. São Paulo: Gazeta Mercantil.

Mcintosh, A. J., \& Siggs, A. (2005). An exploration of the experiential nature of boutique accommodation. Journal of Travel Research, 44(1), 74-81.

Minguet, J. M. (2005). Hotel Design. Barcelona: Monsa.

Oliveira, D. P. R. (1999). Empresa Familiar: como fortalecer o empreendimento e otimizar o processo sucessório. São Paulo: Atlas.

Powers, T., \& Barrows, C. W. (2004). Administração no setor de hospitalidade: turismo, hotelaria, restaurante. São Paulo: Atlas.

Prahalad, C.K., \& Ramaswamy, V. (2004). O futuro da competição: como desenvolver diferenciais inovadores em parceria com os clientes. Rio de Janeiro: Elsevier.

Proserpio, R. (2007). O avanço das redes hoteleiras internacionais no Brasil. São Paulo: Aleph.

Rabontu, C. I., \& Niculescu, G. (2009). Boutique hotels: new appearances in hotel industry in Romenia. Annals of the University of Petrosani, Economics, 9(2), 209-214.

Ritchie, J. R. B., Tung, V. W. S., \& Ritchie, R. J. B. (2010). Tourism experience management research: emergence, evolution and future directions. International Journal of Contemporary Hospitality Management, 23(4), 419-438.

Rogerson, J. M. (2010). The boutique hotel industry in South Africa: definition, scope, and organization. Urban Forum, 21(4), 425-439.

Russell, J. (2008, March 25). Boutique \& lifestyle hotels. USA Today. Recuperado em 11 de dezembro de 2011, de http://www.usatoday.com/travel/hotels/.

Swarbrooke, J., \& Horner, S. (2002). O comportamento do consumidor no turismo. São Paulo: Aleph. 
Teo, P., \& Chang, T. C. (2009). Singapore's postcolonial landscape: boutique hotels as agents. In T. Winter, P. Teo, \& T. C. Chang (Eds.), Asia on tour: exploring the rise of Asian tourism (pp. 81-96).

Tuch, D. L., \& Spolon, A. P. G. (2004). Planejamento hoteleiro. In M.G.R. Ansarah. Turismo. Como aprender, como ensinar - Vol.2 (pp. 353-374). São Paulo: Editora SENAC.

Vallen, G. K., \& Vallen, J. J. (2003). Check-in, check-out: gestão e prestação de serviços em hotelaria. Porto Alegre: Bookman.

Wheeler, D. F. (2006). Understanding the value of Boutique Hotels (Dissertação de Mestrado).

Massachusetts Institute of Technology, Cambridge, MA.

Artigo recebido em: 21/10/2012.

Artigo aprovado em: 07/11/2012. 